\title{
En defensa de la gramática: el modelo de enseñanza de la lengua de Ricardo Monner Sans
}

\author{
Defending grammar: the language teaching program of Ricardo Monner Sans
}

\author{
Esteban Lidgett \\ CONICET/Universidad de Buenos Aires, Argentina
}

\begin{abstract}
Resumen:
Este trabajo pretende contribuir al estudio global de las ideologías lingüísticas que circulan en la prensa especializada argentina durante las primeras décadas del silgo XX. En particular, se propone un análisis de las intervenciones de Ricardo Monner Sans en la prensa especializada, referidas a la cuestión de la enseñanza de la lengua. El corpus, constituido por cuatro artículos publicados en dos revistas culturales: la Revista de Historia, Derecho y Letras y la Revista de la Universidad de Buenos Aires, constituye un insumo imprescindible para examinar la conformación de un modelo de enseñanza de la lengua que pretende sintetizar la tradición gramatical escolar con un objetivo pedagógico concreto: la estigmatización de los usos lingüísticos que se apartan de la norma culta. A partir del análisis de estos artículos se busca deslindar la concepción ideológica lingüística que subyace al modelo de enseñanza de la lengua que propone el autor, su contraste con el enfoque asumido oficialmente tras la reforma educativa de 1905 y su vinculación con el discurso nacionalista pro hispánico que emerge en la Argentina hacia fines del XIX y comienzos del XX.
\end{abstract}

Palabras clave: Gramática escolar, Ricardo Monner Sans, Argentina, Comienzos del siglo XX.

\section{ABstract:}

This paper aims to contribute to the global study of the linguistic ideologies circulating in Argentinean specialized press during the first decades of the XX century. In particular, it is proposed an analysis of Ricardo Monner Sans's interventions in the specialized press referring to language teaching. The corpus consists of four articles published in two cultural journals: Revista de Historia, Derecho y Letras and Revista de la Universidad de Buenos Aires. It constitutes an essential input to examine the formation of a language-teaching model that aims to synthesize the school grammatical tradition with a specific pedagogical objective: the stigmatization of linguistic uses that deviate from the standard. From the analysis of these articles, it is sought to demarcate the ideological linguistic conception that underlies the language teaching model proposed by the author, its contrast with the approach officially assumed after the educational reform of 1905 and its link with a pro-Hispanic nationalist discourse which emerges in Argentina towards the end of 19 th century and the beginning of 20th.

KEYWORDS: School grammar, Ricardo Monner Sans, Argentina, Early 20th Century.

\section{INTRODUCCIÓN}

Desde su constitución como contenido obligatorio para los colegios nacionales en los planes de estudio de 1863 (cfr. Toscano y García y García Folgado 2012, Lidgett 2017), año en que se nacionaliza la educación secundaria, la gramática ha sido considerada un instrumento esencial para la enseñanza de la lengua materna. A tal punto se verifica este hecho, que incluso si se dejara de lado la extensa producción de gramáticas escolares en el período que va de 1863 a $1922^{1}$, sería posible reconstruir en los diversos paratextos de estas gramáticas, así como en las diferentes publicaciones periódicas especializadas, un extenso debate que reconocería distintas etapas, siempre en conexión con las sucesivas reformas de los planes de estudio, en torno a la necesidad de profundizar la enseñanza de la gramática o a la conveniencia de modificar los métodos elaborados para ese fin.

La profusa circulación de estos debates en la prensa periódica, incluso por fuera de los ámbitos estrictamente vinculados a la divulgación educativa, no podría explicarse si no se comprendiera la decisiva relevancia que adopta la cuestión de la lengua, no solo al interior del sistema educativo sino también para el debate cultural que, entre fines del siglo XIX y comienzos del XX, se desarrolla en torno al par lengua/nación (cfr. Alfón 2011, Ennis 2007). En ese sentido, no sería aventurado afirmar que el proceso de construcción 
y organización de la nación hacia fines del siglo XIX deposita en el sistema educativo la tarea de fomentar y reafirmar una identidad nacional sobre la base de distintos órdenes simbólicos entre los que la lengua adquiere un lugar destacado.

En efecto, como ha sido señalado con frecuencia por la crítica, particularmente desde mediados de la década de 1880, el Monitor de la Educación Común, órgano oficial de publicaciones del Consejo Nacional de Educación, ha dejado claros testimonios de la preocupación por el destino de la lengua nacional en el contexto de una sociedad cosmopolita y abierta al flujo migratorio (cfr. Di Tullio 2002 y 2003, López García 2009, Vázquez Villanueva 2006). Un caso emblemático al respecto, precisamente porque trasciende las fronteras del ámbito educativo, es el de la "Circular" que el ministro de Instrucción Juan Carballido (1891a y 1891b) publica en el diario La Nación ${ }^{2}$, para difundir los fundamentos de la reforma educativa que propiciaba. Su publicación de la "Circular" en un medio de prensa de alcance nacional revela la voluntad del ministro de intervenir más allá del ámbito educativo, y su contenido evidencia la importancia que el problema de la lengua -y, en particular, el de su enseñanza- tenía para las autoridades ministeriales:

Más que la raza y las instituciones análogas, constituye el vínculo de fraternidad el tesoro inapreciable de la lengua común [...].
Pero, tiende a adulterarse rápidamente la lengua patria, a transformarse en cada región con el fermento dialectal. Nadie más
que nosotros está expuesto a este peligro. Y si puede ser una exageración prever un día en que nos fuera difícil de entendernos
entre hispano-americanos, no lo sería asegurar que habríamos perdido, a no reaccionar, el hábito de la lengua tradicional,
la apreciación exacta de las mismas bellezas literarias y que, después de la diferencia del acento, la variedad del gusto y del
estilo acontecería más y más la separación. La reacción y el remedio están en el estudio de nuestra lengua. Renunciamos
a vanagloriarnos con nuestras incorrecciones: como lo repite extensamente el nuevo plan de estudios, no hay más idioma
nacional que el castellano. (Carballido, 1891a: 3)

La idea de una lengua común que constituye un vínculo de confraternidad con el mundo hispánico es enarbolada por el ministro como un objetivo que la enseñanza del idioma debe perseguir para evitar la fragmentación dialectal. El peligro de dialectalización es tanto mayor en la Argentina cuanto que, como sostiene el ministro en la segunda parte de la "Circular", en estas tierras "están sufriendo una alteración profunda todos los elementos nacionales: lenguas, instituciones, prácticas, gustos e ideas tradicionales”, como consecuencia de la "violenta avenida inmigratoria" (1891b: 3).

Dos años antes de aquel testimonio de la voluntad política de intervenir en la dirección educativa para controlar la "corrupción lingüística", Ricardo Monner Sans (1853-1927) arribaba a la Argentina. De vasta carrera diplomática y periodística y con alguna afición a los estudios filológicos, Monner Sans encuentra rápidamente una carrera profesional en la prensa y en la escuela ${ }^{3}$. En 1893 , ya como profesor titular de castellano en el Colegio Nacional de Buenos Aires, publica para los tres primeros años de la educación secundaria una Gramática castellana (1893) que se ajusta a los programas oficiales delineados tras la reforma de Carballido.

Casi una década más tarde, y tras la querella desplegada en torno al libro de Abeille (1900) sobre el idioma de los argentinos, Monner Sans irrumpe en el debate sobre la lengua con la publicación de Notas al castellano en la Argentina (1903), un extenso repertorio de voces locales que pretende distinguir entre los neologismos aceptables y los meros "barbarismos". Es decir, entre aquellas voces que el autor considera aportes singulares de las variedades autóctonas y que, por tanto, pueden ser incorporadas a la norma culta; y aquellas otras que estima que son incorporaciones foráneas, provenientes sobre todo de las lenguas inmigratorias, y que deberían ser censuradas para evitar la corrupción lingüística. Los dos prólogos con que cuenta esa obra, uno escrito por Estanislao Zeballos y otro por el mismo autor, coinciden a grandes rasgos en señalar que el problema de la lengua nacional era el peligro de su corrupción debido a la masiva afluencia inmigratoria; aunque Monner Sans también agrega a las causas de este mal el contacto con la cultura francesa y las "malas traducciones" de literatura extranjera.

La polémica recepción de sus Notas, que por entonces despertó en la prensa una disputa entre detractores y apologistas de la obra ${ }^{4}$, otorgó mayor notoriedad a la figura del polemista Monner Sans y le concedió, 
en los años siguientes, un espacio destacado como autoridad en materia educativa. La presencia de la obra gramatical de este autor como texto de referencia en los programas escolares ${ }^{5}$, así como la amplia recepción de sus artículos filológicos en diversos medios de prensa ${ }^{6}$, evidencian la relevancia que este autor alcanzó no solo en el ámbito educativo sino también en los diversos foros de debates sobre cuestiones filológicas y lingüísticas.

Entre la vasta producción periodística de Monner Sans durante sus años en la Argentina existe una serie de artículos sobre enseñanza de la lengua que se publican en dos órganos de la prensa especializada: la Revista de Derecho, Historia y Letras de Estanislao Zeballos y la Revista de la Universidad de Buenos Aires ${ }^{7}$. Esta serie constituye un documento de la voluntad del gramático de intervenir en la reforma de planificación educativa a nivel nacional. Su participación en la comisión asesora que elabora el plan de estudio de la administración Garro en 1912 (cfr. Lidgett 2017), por su parte, revela hasta qué punto estas intervenciones lograron efectivamente concretarse y definieron un modelo de enseñanza de la lengua que acabaría por consolidarse al menos durante las dos décadas siguientes.

El derrotero que va del primero de estos artículos, publicado en 1904 en la RDHL; hasta el último, publicado en la RUBA en 1913, evidencia, además de la preocupación personal del autor durante esos años por las cuestiones pedagógicas referidas a la enseñanza de la gramática, la definición de un proyecto de enseñanza de la lengua, cuyos antecedentes se remontan según dijimos a la "Circular" de Carballido. Asimismo, el tono polémico que, como veremos, asumen algunos de estos artículos permite analizar el contraste de este modelo de enseñanza con el que, a partir de 1905, comienza a gestarse durante la administración de Joaquín V. González en el Ministerio de Justicia e Instrucción Pública. Esta disputa entre un modelo de enseñanza prescriptivo y centrado en la gramática, como el que propone Monner Sans, y otro que asume el desplazamiento de la gramática a favor de la retórica, como el que presenta González, constituye un episodio central en la historia de la enseñanza de la lengua en la Argentina, por cuanto pone en contraste dos formas antagónicas de proyectar la lengua como objeto de enseñanza.

\section{GRAMÁTICA O RETÓRICA: DOS ORIENTACIONES EN LA ENSEÑANZA DE LA LENGUA}

La configuración de la gramática como disciplina escolar en los colegios nacionales de la Argentina se produjo en el contexto de la conformación del Estado nacional. El vínculo entre estos dos procesos se expresa con claridad en la proliferación, durante las últimas décadas del siglo XIX y las primeras del XX, de una legislación educativa centralizada que buscaba regular desde la planificación del sistema educativo hasta los contenidos de los programas de las asignaturas. Existe cierto consenso entre la bibliografía crítica acerca de que, en la Argentina, una de las tareas principales de la gestión estatal durante la segunda mitad del siglo XIX tenía que ver con la necesidad de moldear la identidad colectiva del pueblo como una entidad cultural y lingüísticamente homogénea (cfr. Bertoni 2001, Di Tullio 2003). Este proceso requería sobre todo un modelo de lengua de Estado, asociado a una concepción particular de la nación, que intentaría imponerse y consolidarse a través del sistema educativo centralizado.

De acuerdo con Bertoni (2001: 171-172), hacia la década del 90 del siglo XIX existían dos formulaciones sobre la nación: una contractualista, de matriz cosmopolita, que "delineó una idea de nacionalidad concebida como producto de la mezcla, del crisol de razas"; y una cultural esencialista, que consideraba "la idea de una nacionalidad ya existente, establecida en el pasado, de rasgos definidos y permanentes". En la misma línea que Bertoni, Vázquez Villanueva (2006: 102) se refiere a "un nacionalismo de matriz genealógica y excluyente centrado en la singularidad cultural” que a partir de la década 1890, y como reacción al fenómeno inmigratorio, se opondría a otro "nacionalismo de carácter inclusivo y liberal”, más característico de la década anterior. En el ámbito del sistema educativo, siguiendo a Vázquez Villanueva (2006), los primeros pasos hacia la elaboración de este nacionalismo genealógico se encuentran ya en la creación del Consejo Nacional de Educación, en 1881, "que refiere la intención de extender junto con la educación pública, los valores 
otorgados a todo aquello que incluyera la cultura nacional [...] como una estrategia para cumplir con el principio de 'educar argentinamente'”. Posteriormente, la celebración del Primer Congreso Pedagógico en la Argentina trae como consecuencia la redacción de la Ley 1420 en 1884, en la que, según la autora, "se formula la orientación nacional de la educación argentina" (2006: 106). Estos antecedentes confluirán, hacia principios de la década de 1890, con la revalorización de la tradición cultural del hispanismo que se produce en Argentina en el marco de las celebraciones por el cuadringentésimo aniversario de la llegada de Colón a América. En ese contexto, signado también por el panamericanismo que cobró fuerza tras la Primera Conferencia de Washington ${ }^{8}$, la "Circular" de Carballido reafirma un proyecto educativo cuya concepción de la enseñanza de la lengua es indisociable de esta idea genealógica de nación.

En efecto, el modelo de educación lingüística que Monner Sans se encargará de definir con precisión en los artículos que analizamos, pretende dar respuesta a lo que se percibía como una desintegración de la comunidad lingüística producto del aluvión inmigratorio. Este temor de disgregación social, que -como analiza Di Tulli (2003) - excede el ámbito estrictamente lingüístico, constituye hacia fines del siglo XIX un factor ineludible para analizar las actitudes de la población hacia la lengua extranjera. Al mismo tiempo, como sostiene López García (2012: 121), explica la emergencia de un proceso de gramatización que no solo "ofrece una representación de la lengua, sino que además regula los espacios sociales”. En ese contexto, la gramática escolar se consolida como un instrumento apto para moldear la lengua nacional conforme al modelo de cultura monoglósica y de sociedad estratificada que propone la Generación del 80.

Estas consideraciones permitirían afirmar que, durante las últimas dos décadas del XIX y la primera del XX, los debates fundamentales con relación a la configuración de la gramática escolar en los colegios nacionales de la Argentina no se desarrollaron en general en consonancia con el debate entre lengua nacional y norma culta peninsular, es decir, con relación a la aceptación o no de una norma autóctona distinta de la española; sino que se centraron en torno a la definición de una gramática adecuada para dar respuesta a los modelos de ciudadanía que promovían los distintos proyectos nacionales de la élite gobernante ${ }^{9}$. En ese sentido, sí es posible encontrar una vinculación entre el proyecto nacionalista pro-hispánico de fines del XIX y principios del XX y el surgimiento de un modelo de enseñanza de la lengua que promovía la gramática como un instrumento prescriptivo y correctivo, tendiente a censurar los usos que se apartaban de la norma culta peninsular. Este modelo, lejos de representar una reacción al nacionalismo lingüístico que promovía una norma propia, como el defendido por Abeille (1900), parece antes bien la consecuencia directa de la proyección sobre el sistema educativo de un discurso nacionalista que reacciona frente a lo que considera una desintegración cultural favorecida por la inmigración masiva. La estigmatización de los "barbarismos" y el celo por la corrección funcionarían así como esquemas de segregación hacia los elementos disolventes de la lengua y de la sociedad.

Esta concepción de la enseñanza de la lengua, que pretendía adaptarse a la supuesta amenaza de corrupción derivada del proceso inmigratorio, contrastó visiblemente con los objetivos que la enseñanza lingüística había asumido en los colegios secundarios desde su nacionalización en 1863, de la mano del proyecto ilustrado de Amadeo Jacques. Como ha sido expuesto extensamente en Blanco (2004), el proyecto educativo de Jacques en 1863 estuvo orientado a formar a la clase dirigente que el proyecto liberal mitrista necesitaba para organizar a la nación. En ese modelo, la enseñanza de la lengua se basó sobre todo en las prácticas de lectura y escritura, que ingresaron en los contenidos de los programas como retórica y composición. El surgimiento del modelo gramatical escolar que se verifica desde la década del 80, en cambio, desplazó la formación letrada de los programas de castellano a favor de un incremento de una formación gramatical destinada particularmente a la corrección de los "vicios". Este desplazamiento no solo implicó un cambio de orientación pedagógica en cuanto a lo que se consideraba indispensable enseñar en la escuela secundaria, sino también una redefinición de los objetivos sociales para los que se había pensado la escuela media. En efecto, si el proyecto liberal mitrista había considerado la enseñanza media como un dispositivo orientado a formar de manera integral a la nueva élite ilustrada necesaria para ejercer las funciones públicas, el proyecto positivista de la generación del 80, por 
su parte, la consideró un instrumento de cohesión social y de construcción de la identidad nacional. En el ámbito de la enseñanza de la lengua, este proyecto supuso la consolidación de un modelo gramatical escolar cuyo principal objetivo pedagógico consistió en la reafirmación de una identidad lingüística sustentada en el ideal de uniformidad de la cultura monoglósica.

En la historia de la enseñanza de la lengua, no obstante, este modelo gramatical escolar, que encuentra en la "Circular" de Carballido su más clara exposición de principios, presenta un punto de inflexión cuando en 1905, el ministro González encarga a Leopoldo Lugones la elaboración de los nuevos programas. Lugones, a cargo de la Inspección General de la Enseñanza Secundaria desde 1904, organiza una serie de conferencias pedagógicas con el fin de sentar las bases de lo que definiría como la nueva escuela media: "integral en sus fines y científica en sus medios" (1910: 85). Ferviente defensor de la pedagogía integral de Jacques, Lugones se opone desde el principio de su gestión a los planes instrumentados durante las últimas décadas y pone de manifiesto la necesidad de retomar las bases establecidas por el proyecto de 1863.

El nuevo plan establece una instrucción general de 6 años, preparatoria a la vez para la vida laboral y para la formación superior y equilibrada en la cantidad de lecciones dedicadas a la formación humanística y a la científica ${ }^{10}$. En relación con la formación lingüística, se suprime la enseñanza de lenguas clásicas, se disminuye la cantidad de lecciones semanales de Castellano, se aumenta una lección más para las Lenguas modernas y se agregan lecciones semanales para Literatura, que antes estaba incluida en la asignatura Castellano.

A partir de esta reforma, el programa oficial de Castellano promueve la necesidad de fomentar nuevamente las habilidades de lectura y escritura, haciendo particular énfasis en la composición, la escritura de cartas y la lectura de autores modernos nacionales y extranjeros. De acuerdo con el programa presentado en el Boletín Oficial en 1905, la enseñanza de la gramática, que desde 1891 abarcaba casi la totalidad de los contenidos de los tres primeros años de la asignatura, queda ahora relegada a una posición subsidiaria, y en su lugar, vuelven a aparecer los contenidos vinculados con la retórica: lectura y composición ${ }^{11}$. La analogía, la sintaxis y la ortografía solo aparecen en último lugar y siempre en conexión con las prácticas de lectura y escritura.

Resulta particularmente destacable la presencia en el programa de una ejercitación referida a la escritura y la necesidad de articular la enseñanza gramatical con esa práctica. De acuerdo con Delgado (1947: 30), estos programas son fundamentales por cuanto manifiestan por primera vez "la insistencia del pensamiento oficial en conformar la regla gramatical a la urdimbre de la lengua viva". En ese sentido -continúa esta autora- "la lectura y su captación estética serán norma precisa para llegar a lo otro: la regla gramatical”. En el programa también se omiten las referencias a la corrección de los "vicios de dicción" y "de construcción", presentes en los programas anteriores desde 1892. Asimismo, se eliminan el análisis lógico y la etimología, que habían sido dos pilares de la tradición gramatical.

\section{Contra la RETórica}

Es en este contexto que Monner Sans emprende, desde la tribuna de la RDHL y de la RUBA, la defensa del modelo de enseñanza de la lengua propuesto por Carballido, del que su propia gramática era uno de los exponentes más fieles. Los primeros dos artículos, publicados en 1904, uno en la RDHL y otro en el primer nmero de la RUBA, son anteriores a la reforma de González y Lugones y, en términos generales, revelan la voluntad del autor de intervenir en la elaboración de un plan de enseñanza del idioma nacional, precisamente cuando ya se avizoraban los nuevos aires de reforma en el ámbito educativo.

El primero de estos artículos consiste en la definición de un plan de enseñanza de la lengua para los colegios nacionales. Interpelado por las continuas reformas que desde fines del XIX venían sucediéndose en la escuela media, Monner Sans comienza su artículo definiendo lo que considera que debería ser el objetivo central de la enseñanza de la lengua, a saber la remoción de "fragmentos de idiomas exóticos" y "residuos de lenguas menos ricas y variadas que la nuestra" (1904a: 499). En consonancia con el planteo acerca del problema de la lengua nacional que había exhibido en sus Notas, el autor plantea en este artículo la necesidad de que el 
sistema educativo vuelva a poner en el centro de sus objetivos pedagógicos la función prescriptiva y correctora de la gramática escolar.

En un contexto de "corrupción lingüística" como el que imaginaba Monner Sans, la decisión de las autoridades de retomar una propuesta educativa que relegaba el lugar la tradicional gramática escolar a una posición subsidiaria y focalizaba, en cambio, los contenidos vinculados a la retórica es considerada como un error estratégico en la planificación:

No queremos indagar los motivos, mas lo cierto es, y de fácil probanza, que si en lo legislado referente á la enseñanza del patrio idioma reinó, por lo general, censurable confusión, en los libros de texto imperó como regla común el desconocimiento completo de las dificultades que ha presentado en todo tiempo la enseñanza del lenguaje. Dejando á un lado que el habla del profesor pugna con lamentable frecuencia con las reglas que enseña, apena y contribula dar con obras gramaticales en las que sale la gramática maltrecha o antologías argentinas confeccionadas con tan dudoso gusto literario que más parecen retazos sacados a la pública vergüenza para ludibrio de sus autores, que páginas escogidas para contribuir á formar el gusto de generaciones que nos van sucediendo. (1904a: 500)

La "censurable confusión" que el autor imputa a las legislaciones previas sobre la enseñanza del idioma tendría su origen en el desconocimiento de las dificultades propias de la asignatura. Dichas dificultades, no obstante, son para Monner Sans más propias de los métodos y de los instrumentos utilizados para la enseñanza de la gramática que de los contenidos teóricos de la disciplina. Esta imputación a los instrumentos pedagógicos alcanza particularmente a las antologías literarias que, desde la reforma del ministro Juan Ramón Fernández (en 1903), incluían textos de literatura extrajera además de los consabidos clásicos de la literatura española y nacional ${ }^{12}$.

En las antípodas de esta reforma, la propuesta de Monner Sans apunta a reforzar el estudio de la gramática a partir de la aplicación de reglas negativas, centradas en la corrección de los usos no normativos; y el de la literatura como proveedora del modelo de bien decir: "en gramática y en literatura las reglas son negativas; al talento y al genio les queda reservado el crear los modelos en que vamos todos a librar las bellezas de dicción" (1904a: 501). Esta concepción de la gramática coincide con la "nueva cultura del idioma" que, de acuerdo con Di Tullio (2002: 284), acompañó al modelo positivista que se había instalado en el Consejo Nacional de Educación desde mediados de 1880. Dicha cultura, que la escuela debía proveer a los alumnos, consistía básicamente en dos operaciones: "una negativa, borrar las malas influencias que el niño traía de su casa -los vulgarismos de las clases bajas y los barbarismos de las altas-; la otra positiva, ampliar la cultura del idioma, sobre todo mediante el enriquecimiento del léxico"13.

En ese sentido, la propuesta para la enseñanza de la lengua materna que esgrime Monner Sans supone, además de la reafirmación del valor correctivo de la gramática, una reversión del orden de sus partes:

Siguióse hasta hoy en la Peninsula y en la América latina el orden de antiguo establecido. La Gramática se divide en cuatro partes: Analogía, Sintáxis, Prosodia y Ortografía y hasta ahora no se creyó conveniente modificar tal orden, y el estudio gramatical comenzó por el análisis, siguióle luego la síntesis, nos enseñaron mas tarde á pronunciar y aprendimos finalmente á exteriorizar con la palabra escrita el fenómeno de nuestros pensamientos. (Monner Sans, 1904a: 502)

De acuerdo con el gramático catalán, este orden sería acertado si se tuviera que enseñar el castellano “a quien llegase a cierta edad desconociéndolo por completo"; no obstante, como se lo va a enseñar a quien lo posee como lengua materna, "lógica y razón adunadas nos aconsejan seguir en el estudio gramatical el orden impuesto por la naturaleza” (1904a: 502). Este orden natural, según Monner Sans (1904a: 502-503), suponía comenzar por la ortografía y la prosodia, pues lo primero que "urge es dotarle de correcta ortografía y clara pronunciación, para evitar ambigüedades o erróneas interpretaciones”; luego debía continuarse con la analogía, "un estudio de descomposición necesario a quien está empezando a componer de continuo", ya que "mal se agrupan los elementos cuando se ignoran sus propiedades"; en tercer lugar, vendría la sintaxis, cuyo estudio podría acometerse "briosamente", "pues pues ya no nos preocupan ni una defectuosa ortografía ni una viciosa pronunciación, ni la ignorancia del valor independiente de cada vocablo”; y, finalmente, 
[...] destinamos el curso a unas breves nociones de retórica y de literatura española y americana, estudios ambos de poco vuelo, pero lo suficiente para que se adquieran noticias generales y se sepa quienes en ambos hemisferios descollaron manejando con envidiable galanura el lenguaje. (Monner Sans, 1904a: 502-503)

La necesidad de anteponer la gramática a la retórica en una sociedad amenazada por el aluvión inmigratorio vuelve a ser el núcleo de la propuesta de Monner Sans en el siguiente artículo de nuestra serie. En este caso se trata de una carta abierta a Rodolfo Rivarola (1857-1942), publicada en el primer número de la RUBA en 1904, en la que el autor comienza esbozando un diagnóstico sombrío para la enseñanza del idioma en la Argentina:

Se afana el profesor por enseñar teórica y prácticamente el acertado uso del patrio lenguaje, y á los pocos minutos, ya que no á las pocas horas, el alumno recogerá de doctos labios, ó leerá en obras, por otro concepto recomendables, palabras, oraciones y frases en abierta oposición con lo que aprendiera en las clases de idioma [...]. Casos hay en los que los laudables esfuerzos del catedrático de idioma se ven esterilizados por consejos en cuyo seno palpitan la rebeldía y el desprecio por la lengua, que aun bastardeada, tantas hermosuras nos muestra de continuo. (Monner Sans, 1904b: 402)

En contraste con lo que sucede en la Argentina, Monner Sans exhibe el modelo de enseñanza de la lengua en los Estados Unidos. En la perspectiva del autor, la nación del norte padece un contexto inmigratorio de similares dimensiones, pero su sistema educativo habría desarrollado objetivos pedagógicos más claros para evitar la corrupción lingüística. En efecto -sostiene Monner Sans-, mientras en la Argentina "los hispanófobos" "sueñan con inventar una jerga, hija legítima de su ignorancia del espléndido idioma de Castilla”, en Norteamérica, las autoridades educativas son conscientes de la necesidad de defender la lengua nacional (1904b: 435). Para demostrar esto, el autor cita el "Informe de la Comisión de los Diez"14, donde se especifica un planteo del problema muy similar al que él defendía en su artículo anterior:

Si el alumno debe considerar el conocimiento del idioma como un instrumento para expresar sus pensamientos, es necesario que durante el período de la vida en que la imitación es el principio fundamental de la educación, se le aleje lo más posible de la influencia de los malos modelos y se le tenga bajo la de los buenos. (apud. Monner Sans, 1904b: 433)

Monner Sans vuelve a remarcar aquí esta concepción de la enseñanza basada en la consideración de un modelo de lengua negativo (aportado por las reglas gramaticales) y otro ejemplar (propuesto por los modelos literarios), que ya había aparecido en el artículo anterior y que será la base del método pedagógico que delineará en los siguientes artículos.

\section{LOS DOS BANDOS EN CONFLICTO}

A pesar de estos intentos de interceder en la elaboración de propuestas curriculares para la enseñanza del idioma, la reforma de 1905 manifiesta una tendencia diametralmente opuesta a la esbozada por el gramático catalán. El proyecto positivista que Lugones había defendido en las Conferencias Pedagógicas de 1903 y que logra plasmarse en la reforma de González desestima la enseñanza de la gramática y vuelve a ubicar como objetivo pedagógico central para la asignatura Castellano el desarrollo de prácticas de lectura y escritura (véase $\$ 2)$.

En ese contexto, tan desfavorable para su propuesta, Monner Sans vuelve a arremeter desde la RUBA con un artículo titulado "El pleito del lenguaje" (1906). En este caso, su argumento parte de la definición de los "dos bandos" enfrentados en el debate sobre la enseñanza de la lengua: "el que pretende enseñar reglas y cree, al hacerlo, enseñar Gramática, y el que intenta enseñarla analizando trozos escogidos” (1906: 32). Para el autor, quienes apoyan la primera posición sostienen la idea de que "la gramática es un arte, el de hablar y escribir correctamente un idioma" y por lo tanto consideran que hay que partir del estudio de la frase, de las reglas sintácticas que explican su formación. Los del bando contrario, en cambio, consideran que "ni los diccionarios todos ni la Gramática constituyen la lengua, como los códigos de leyes no constituyen la nación”; 
por lo tanto, proponen que es necesario ahondar en algo más que las reglas: "hay que penetrar en su vida [la del lenguaje], que está fuera del vocabulario" (1906: 33).

La estrategia argumentativa de Monner Sans en este caso no buscará la abierta oposición a la segunda de estas posturas, sino un intento de conciliación entre ambas posiciones, partiendo de la necesidad de defender el mismo objetivo pedagógico que había definido en 1904: la depuración de los vicios y la exhibición de modelos de lengua castiza. En ese sentido, el autor considera que el estudio de las reglas no se debe oponer al del lenguaje en uso; antes bien, las primeras deberían constituir solo una técnica para la utilización del lenguaje (1906: 34):

Al talento natural hay que agregar el estudio de las reglas y de los modelos [...] aunque aquellas sean la lógica consecuencia de estos, porque en unas veremos lo que no debemos hacer, y en otros el resultado de los que se ha hecho. La fusión de lo negativo y lo positivo nos dará el dominio de un arte cualquiera.

Monner Sans vuelve a esbozar aquí uno de los objetivos pedagógicos centrales que mantiene intacto en las sucesivas ediciones de su gramática: la idea de que las reglas sirven para censurar los usos desviados, mientras que los modelos, a los que se accede a través de los ejemplos, constituyen la norma a la que debe ajustarse el alumno. La enseñanza de la lengua, entonces, debe orientarse a una doble función: una negativa-prescriptiva y otra positiva-ejemplar. La primera se exhibirá en la gramática de Monner Sans a partir de una selección de usos cotidianos que se apartan de la norma y que se exhiben como modelos negativos que los alumnos deben corregir aplicando las reglas de la gramática y remitiendo la norma a la etimología y al uso de los hombres doctos (cfr. Lidgett 2011). La segunda función se ejercitará a partir de los ejemplos literarios, que deben ajustarse a una cuidada selección de autores peninsulares y americanos. De esta forma, las dos posiciones que se mencionaban al comienzo del artículo encuentran una síntesis apropiada en este modelo de enseñanza, del que la gramática de Monner Sans sería un ejemplo acabado.

En defensa de su posición, el autor critica a quienes, para oponerse al estudio de las reglas, justifican que "lo fundamental es la idea" y que "la palabra es a la sumo un signo o sonido convencional, que por lo mismo puede variarse a voluntad" (1906a: 34). En contraposición, el autor sostiene que esa convención no es un mero accidente, sino el producto de una historia y de una tradición:

Las palabras son partes constitutivas de un gran caudal heredado que no debemos dilapidar; [...] las voces tienen su historia y su valor preciso, exacto, impuesto por radicales, raíces, flexiones, y desinencias, y $[. .$.$] es irreverente, sino criminal, que alguien,$ por su sola voluntad, quiera anular valores y borrar historias. (Monner Sans, 1906: 34-35)

De esta forma, el estudio de la etimología ${ }^{15}$ aporta una justificación histórica que explica la razón de ser de las reglas que gobiernan la gramática y las vincula con una tradición específica. En ese sentido, Monner Sans sentencia que "la gramática castellana no tan solo es arte, sino ciencia": las dos perspectivas se sintetizan en un modelo de enseñanza gramatical, aportando la primera el modelo negativo-prescriptivo y la segunda la justificación histórica que ampara a la norma.

\section{LA RESTAURACIÓN DEL MODELO GRAMATICAL}

El modelo de enseñanza de la lengua defendido por Monner Sans finalmente logrará imponerse cuando, en el contexto de la nueva reforma de los planes de estudio de 1912, el entonces ministerio Juan Garro convoque al gramático para que integre la comisión encargada de elaborar los planes de Castellano ${ }^{16}$. El nuevo plan retoma la tradición gramatical escolar inaugurada por Carballido y vuelve a incluir los contenidos de gramática histórica ("nociones de lingüística y etimología") que habían desaparecido en 1905 (véase nota 15). Asimismo, entre los "fines de la enseñanza" que señala el decreto, siguiendo la tradición inaugurada por Carballido y largamente defendida por Monner Sans, se hace referencia a la necesidad de "depuración y enriquecimiento del vocabulario y de las formas" (Garro, 1913: 18). 
En este contexto ya más favorable a su propuesta, Monner Sans emprende una defensa de este nuevo plan de enseñanza en el último artículo de nuestra serie, publicado en 1913 en la RUBA con el título "La enseñanza del Castellano". En esta oportunidad, el autor parte de la justificación de la organización de los contenidos en el programa de Castellano (1913: 49):

Comenzamos por la prosodia [...] porque de ella deriva el arte de la lectura. [...] El aprender a leer bien nos llevaría como de la mano a las lecturas públicas, complemento necesario de la cultura literaria. [...] Pero, ¿qué debe leerse? [...] Sin ánimos de herir ni molestar á nadie, bien puedo afirmar que es empresa de titanes el arreglo de una antología argentina, que, como complemento de la castellana, pudiese servir de libro de lectura en las clases de gramática. Autores hubo, y hay, de robusto cerebro, que pensaron hondo, y supieron expresar con claridad y elegancia sus ideas. [...]. Pero ¿se sigue de aquí que cualquiera de las páginas por ellos escritas se puede ofrecer á los alumnos como modelo de lenguaje? No, porque son dos cosas que, por desgracia, se presentan á veces divorciadas, la honda concepción y la forma externa de esa concepción.

Siguiendo la posición desplegada en su artículo de 1906, Monner Sans considera que la enseñanza de la prosodia requiere la exhibición de un modelo positivo para el alumno. Sin embargo, en la búsqueda de ese modelo, el autor descarta la posibilidad de una antología de literatura nacional, señalando que si bien en ella se exhibe un valor literario los textos podrían contener incorrecciones perniciosas para la enseñanza gramatical. En ese sentido, Monner Sans se pregunta "¿por qué la Universidad no nombra en su seno una comisión encargada de pulir aquellas páginas?”, pues “desaparecidas aquellas leves manchas, trocadas las páginas ó las obras en impolutas, pudieran ofrecerse sin recelo á la juventud como modelos de elocuencia” (1913: 51).

$\mathrm{Al}$ estudio de la prosodia, centrado en el ejercicio de la elocución, debe seguirle durante el primer año, según Monner Sans, el de la ortografía, que aporta las reglas para la correcta escritura, y posteriormente el de la analogía y el de la sintaxis, "que nos ha de permitir penetrar en el alma de nuestro idioma" (1913: 53). En relación con estas partes de la gramática, el autor vuelve a proponer la doble finalidad prescriptiva y ejemplificadora de la gramática escolar (1913: 53):

Cada lengua tiene su construcción propia; y si hay pecado y grave, en emprender un discurso de neologismos innecesarios [...], más que pecado, hay crimen en desfigurar el heredado lenguaje con giros extraños á la índole de nuestro idioma. [...] Prolijo, por lo tanto, y concienzudo debe ser el estudio de esta parte importantísima de la gramática [al sintaxis], que debe completarse con ejercicios de lectura [...] para hacer notar acertadas concordancias, regímenes especiales, construcciones de indiscutible belleza. [...] No basta el sentido común para inducir reglas de lenguaje. Es necesario estudiar el código en que están, la gramática, y luego saborear las obras magistrales en que dichas reglas aparecen respetadas.

Finalmente, el tercer y último año de estudios gramaticales debe estar dedicado a la lingüística, la base científica de la gramática. En ese sentido, Monner Sans reafirma la articulación de estos estudios con la formación clásica y considera que "restablecido el estudio del latín, este tercer año logrará los atractivos de que antes carecía” (1913: 54). En la perspectiva del autor, la lingüística abarca el estudio de la historia de la lengua, la etimología y algunas nociones básicas de fonética y gramática comparada y su inclusión en el programa se sustenta en el hecho de que aporta una base científica para explicar la procedencia de las reglas y la evolución del idioma (1913: 54):

Soy de los que pienso [...] que la educación clásica influye en gran manera en el porvenir de los pueblos [...] y entiendo que si hemos de aprender primero, para gustar después, las bellezas del lenguaje de las obras de nuestros clásicos y de nuestros hablistas, hemos de adquirir previamente sólidos conocimientos gramaticales, sin olvidar la historia del idioma, á fin de que deje de aparecer á nuestros ojos como mero capricho la evolución del castellano.

La lingüística, entonces, abarca el estudio de la historia de la lengua, la etimología y nociones básicas de fonética y gramática comparada, y constituye el último contenido de la asignatura. Su inclusión se sustenta, según el autor, en el hecho de que aporta una base científica para explicar la procedencia de las reglas y la evolución del idioma. La conclusión de Monner Sans es, finalmente, que se debe "estudiar gramática con independencia de la retórica" pues si bien la lengua es evidentemente familiar a los hablantes, "lo más familiar no es siempre lo más conocido" (1913: 55). 


\section{Conclusiones}

Como ha sido señalado con insistencia en la bibliografía crítica, es evidente que durante las últimas décadas del siglo XIX y las primeras del XX el sistema educativo centralizado que comenzaba a gestarse pretendió dar algunas respuestas a la cuestión social que planteó el fenómeno inmigratorio. La percepción del inmigrante como una potencial amenaza al orden social, alentada por buena parte de la cultura letrada, tuvo su propia expresión en el ámbito educativo. En particular, en lo que respecta a la enseñanza del idioma nacional, la percepción de una inminente peligro de dialectalización promovido por el aluvión inmigratoria sirvió como argumento para sostener un modelo de enseñanza de la lengua sustentado en la corrección de los "vicios" y en la imposición de modelos del "buen decir", prácticas que frecuentemente contrastaron con los usos lingüísticos cotidianos.

En este marco, los textos analizados en este trabajo permiten reconstruir las posiciones de Monner Sans con relación a los objetivos pedagógicos que asume la enseñanza del castellano en la educación secundaria en una etapa en la que la vertiginosa sucesión de reformas educativas plantea, en el ámbito de la lengua nacional, un debate entre dos modelos: uno basado en una tradición gramatical escolar de carácter prescriptivo que se plantea como objetivo el resguardo de la lengua nacional ante las amenazas de "corrupción lingüística"; y otro que, intentando dar respuesta al conflicto pedagógico que suponía la enseñanza de la lengua, busca en la retórica y en la literatura una renovación de los contenidos y de los objetivos de la enseñanza. En esta contienda, Monner Sans plantea un modelo de enseñanza focalizado en los contenidos gramaticales y con una marcada orientación a privilegiar la función correctiva y ejemplificadora de esta disciplina. La participación del autor en la elaboración de los planes de estudio de Castellano que se impondrán tras la reforma de 1912 evidencia la concreción de esta propuesta pedagógica, cuya justificación más clara se halla en el último artículo de la serie textual que analizamos.

En términos más generales, consideramos que las determinaciones que los debates lingüísticos que circulan en el campo intelectual imprimen sobre la definición de los objetivos pedagógicos de la enseñanza de la lengua requieren aún de un pormenorizado análisis en futuras investigaciones. La circulación de estos debates en la prensa escrita, así como elaboración del diseño curricular de las asignaturas vinculadas con la formación lingüística en el sistema educativo nacional, constituyen espacios privilegiados en los que estas determinaciones se hacen evidentes.

\section{Bibliografía}

\section{Fuentes primarias}

Carballido, J. (1891a). Circular: Plan de estudios y programas. En La Nación, Buenos Aires, 19 de abril.

Carballido, J. (1891b). Circular: Plan de estudios y programas. En La Nación, Buenos Aires, 21 de abril.

Comité de los Diez (1904). Informe del Comité de los Diez sobre los estudios de las escuelas secundarias. Buenos Aires: Taller Tipográfico de la Penitenciaría Nacional.

Ferreira, J. A. (1903). Programa de Castellano. En Ministerio de Justicia e Instrucción Pública, Plan de estudios y programas para los Colegios Nacionales de la República Argentina (pp. 13-20). Buenos Aires: Taller Tipográfico de la Penitenciaría Nacional.

Garro, J. (1913). La enseñanza Secundaria. Decretos Orgánicos, Resoluciones de la Dirección General, Planes de Estudios, Programas Analíticos. Buenos Aires: Talleres gráficos de la Penitenciaría Nacional.

González, J. V. (1905). Plan de estudio de los Colegios Nacionales y Escuelas Normales. Boletín oficial de la República Argentina, XIII(3601), 19703-19714.

Lugones, L. (1910). Didáctica. Buenos Aires: Otero y Cía. 
Monner Sans, R. (1904a). Plan para la enseñanza del idioma castellano. Revista de Derecho, Historia y Letras, VI(17), 499-506.

Monner Sans, R. (1904b). La enseñanza del idioma. Revista de la Universidad de Buenos Aires, I(1), 432-436.

Monner Sans, R. (1906). El pleito del lenguaje. Revista de la Universidad de Buenos Aires, III(5), 31-35.

Monner Sans, R. (1913). La enseñanza del castellano. Revista de la Universidad de Buenos Aires, X(22), 43-56.

\section{Fuentes secundarias}

Abeille, L. (1900). Idioma nacional de los argentinos. París: Libraire Emile Bouchon.

Alfón, F. (2011). La querella de la lengua en Argentina (1828-1928). (Tesis doctoral). Universidad Nacional de La Plata, La Plata, Argentina. Recuperado de http://sedici.unlp.edu.ar/bitstream/handle/10915/20882/Docume nto_completo__.pdf?sequence $=1$

Bertoni, L. A. (2001). Patriotas, cosmopolitas y nacionalistas. La construcción de la nacionalidad argentina a fines del siglo XIX. Buenos Aires: FCE.

Delgado, M. J. (1947). La enseñanza del castellano en los Colegios Nacionales de la Argentina. San Miguel de Tucumán: Facultad de Filosofía y Letras de la Universidad Nacional de Tucumán.

Di Tullio, Á. (2002). La otra crisis de la gramática escolar. En G. Parodi (ed.), Lingüistica e Interdisciplinariedad: Desafíos del nuevo milenio. Ensayos en Honor a Marianne Peronard (pp. 281-295). Valparaíso: Ediciones Universitarias de la Universidad Católica de Valparaíso (Chile).

Di Tullio, Á. (2003). Políticas lingüisticas e inmigración. El caso argentino. Buenos Aires: Eudeba.

Dobranich, B. (1900) [1893]. Gramática histórica de la lengua castellana. Nociones de Lingüistica y Etimología. Acompañada de ejercicios. Buenos Aires: Mariano Moreno.

Dussel, I. (1997). Currículum, humanismo y democracia en la enseñanza media (1863-1920). Buenos Aires: FLACSO y Oficina de publicaciones del CBC, Universidad de Buenos Aires.

Ennis, J. A. (2008). Decir la lengua. Debates ideológico-lingüisticos en Argentina desde 1837. Frankfurt am Main: Peter Lang.

Lidgett, E. (2011). Gramática escolar y políticas lingüísticas en la Argentina: un análisis de la Gramática de la lengua castellana (1893) de Baldmar Dobranich y Ricardo Monner Sans. Revista argentina de historiografía lingüistica,3(2), 109-132.

Lidgett, E. (2012). Los inicios de la gramática histórica en la Argentina: un estudio sobre la Gramática histórica de la lengua castellana (1900) de Baldmar Dobranich. En E. Battaner Moro, V. Calvo Fernández y P. Peña Jiménez (comps), Historiografia lingüistica: lineas actuales de investigación (pp. 549-558). Münster: Nodus Publikationen.

Lidgett, E. (2014). La correspondencia Monner Sans - Costa Álvarez (1920-1927): la definición de un programa de investigación filológica en Argentina. Actas de las VI Jornadas Internacionales de Filología y Lingüística y I Jornadas de Crítica Genética: "Lenguas del archivo". Recuperado de: https://filologiaunlp.wordpress.com/2013/05/30/vi-jornadas-internacionales-de-filologia-y-linguistica-y-p rimeras-de-critica-genetica-las-lenguas-del-archivo/

Lidgett, E. (2015). Tradiciones gramaticales y discurso sobre la lengua nacional en la obra de Ricardo Monner Sans (1893-1926). Tesis doctoral inédita.

Lidgett, E. (2017). La consolidación de un modelo gramatical escolar en la enseñanza secundaria Argentina (1863-1936). Boletin de Filología, 52(2), 119-145.

López García, M. (2009). Discusión sobre la lengua nacional en Argentina: posiciones en el debate y repercusiones en la actualidad. Revista de Investigación Lingüistica, 12, 375-397.

López García, M. (2012). Implicancias glotopolíticas del estilo dialógico en los manuales escolares. Páginas de Guarda. Revista de Lenguaje, Edición y Cultura Escrita, 11, 13-31.

Lugones, L. (1903). La reforma educacional. Un ministro y doce académicos. Buenos Aires: S/D.

Monner Sans, J. M. (1929). La vida y la obra de Ricardo Monner Sans, 1853/1927. Buenos Aires: Librería de A. García Santos. 
Monner Sans, R. (1924) [1903]. Notas al castellano en la Argentina. Buenos Aires: Agencia General de Libr. y Publicaciones.

Monner Sans, R. (1922). Mi labor en el Plata, de marzo de 1889 a marzo de 1922. Buenos Aires: Schenone Hnos y Linari.

Solari, M. H. (1949). Historia de la Educación Argentina. Buenos Aires: Paidós.

Tedesco, J. C. (1972). Educación y sociedad en la Argentina (1880-1945). Buenos Aires: Ediciones Solar.

Toscano y García, G. y García Folgado, M. J. (2012). Los textos de gramática en la escuela argentina (1863-1900). Escribas. Revista de Letras, 7, 27-54.

Tulchin, J. (1990). La Argentina y los Estados Unidos. Historia de una desconfianza. Buenos Aires: Planeta.

Vázquez Villanueva, G. (2006). Una política lingüística en el callejón: Hacer la nación, unificar la lengua en Argentina (1890-1900). Revista Lenguaje, 34, 97-123.

\section{Notas}

1 El estudio preliminar que presentan Toscano y García y García Folgado (2012) registra más de un centenar de gramáticas publicadas en la Argentina entre 1963 y 1905. No obstante, la investigación llevada a cabo en el marco del PIP-CONICET "La configuración de la gramática escolar argentina (1863-1922)", cuyos resultados no han sido completamente publicados aún, lleva registrados más de doscientos títulos publicados entre 1863 y 1922.

2 La "Circular", que contiene el texto completo que acompaña al decreto de reforma de los planes de estudio, se publica en cuatro partes en el diario La Nación los días 19, 21, 23 y 25 de abril de 1891. Un análisis más extenso de la "Circular" puede verse en Alfón (2011).

3 Los datos biográficos existentes (cfr. R. Monner Sans 1922 y J. M. Monner Sans 1929) dejan constancia de que durante los años previos a su llegada a la Argentina y tras un breve lapso en el que se desempeñó como diplomático en el Reino de Hawái, Monner Sans colaboró con el periódico La Vanguardia de Barcelona y fundó el boletín Ambos Mundos, donde defendió la unificación cultural y comercial del mundo hispánico ante la amenaza que suponía la creciente influencia de los Estados Unidos en las últimas colonias insulares. Una vez en la Argentina, continúa su labor periodística, trabajando como publicista en La Nación y como corresponsal de El Mercurio de Barcelona. Su labor docente, desempeñada mayormente en el Colegio Nacional de Buenos Aires, se extiende hasta 1922.

4 Tras la publicación de las Notas, el diario La Prensa publica una reseña sin firma con el título "Por los fueros del castellano" (1903), en la que se critica la actitud purista de Monner Sans, quien más tarde responderá en una serie de artículos publicados en El tiempo, bajo el título "Por los fueros de la verdad" (1903). Según afirma Monner Sans en su correspondencia inédita con Costa Álvarez (cfr. Lidgett 2014), el autor de la primera reseña habría sido Antonio Atienza y Medrano, cuya concepción de la enseñanza de la lengua, expuesta en diversos artículos, distaba bastante de la Monner Sans.

5 Como fue dicho, la primera edición de la gramática de Monner Sans se publica en 1893 y la última reedición en vida del autor es la decimosexta de 1926. Las distintas ediciones de su obra fueron ampliadas y adaptadas a las sucesivas variaciones de los planes de estudios y, al menos hasta la reforma de 1936 fueron consideradas obras oficiales para la enseñanza de la gramática en los colegios nacionales (cfr. Lidgett 2015).

6 Además de los artículos que se analizan aquí, Monner Sans cuenta con una extensa cantidad de colaboraciones en la prensa periódica y especializada, sobre diversas cuestiones filológicas e históricas. Una lista exhaustiva de sus trabajos puede hallarse en R. Monner Sans (1922).

7 En adelante mencionaremos las revistas como RDHL y RUBA, respectivamente. Los cuatro artículos son: "Plan para la enseñanza del idioma castellano" (1904a); "La enseñanza del idioma" (1904b); "El pleito del lenguaje" (1906) y "La enseñanza del castellano" (1913).

8 La Primera Conferencia de Washington de 1889 fue impulsada por los Estados Unidos con el objetivo de lograr una unidad aduanera americana. La posición de la delegación argentina, que se opone a lo que considera un intento de imperialismo norteamericano, impulsará una reacción solidaria entre los sectores pro-hispánicos del medio local que apoyarán la postura argentina en nombre de la confraternidad hispano-argentina y de la unidad racial y lingüística. Sobre la participación de los delegados argentinos, Manuel Quintana y Roque Saénz Peña, quienes se opusieron las medidas de libre comercio con Estados Unidos, puede consultarse Tulchin (1990). Para un análisis más detallado de los efectos de esta Conferencia en el nacionalismo cultural argentino véase también Bertoni (2001).

9 En efecto, es posible considerar que la adopción de la norma culta peninsular como código de referencia, si bien se acentúa en el contexto de la cuestión inmigratoria y el auge del nacionalismo pro hispánico, constituye una tendencia 
mayoritaria en la gramática escolar independientemente de este contexto, quizás como consecuencia directa del peso de la tradición gramatical hispánica sobre las obras y los autores locales. Esto permitiría explicar el hecho de que, incluso en los momentos en que las autoridades ministeriales pregonaban una política nacionalista que procuraba tomar distancia de la antigua metrópoli, la tradición gramatical difícilmente reflejó esta tendencia en sus elecciones teóricas.

10 La diatriba entre quienes defendían la orientación científica de la educación secundaria y quienes promovían la humanista atraviesa distintos debates vinculados con las diversas reformas de los planes entre fines del XIX y principios del XX (cfr. Dusel 1997, Solari 1949, Tedesco 1972). En relación con el debate que presentamos aquí en torno a la enseñanza de la lengua, los partidarios del modelo humanista (como Carballido o Monner Sans) promovían la enseñanza de las lenguas clásicas, mientras que quienes sostenían el modelo de enseñanza científica consideraban inútiles las lenguas muertas y en cambio, impulsaban una mayor dedicación de horas para las lenguas modernas. En esta línea, en los considerandos de la reforma de 1905, publicados en el Boletín Oficial (González 1905: 19705), se dice al respecto: “el criterio de utilidad relativa de ambas lenguas [latín y griego] no acepta ya emplear en ese aprendizaje una suma de tiempo considerable, arrebatado sin provecho cierto a otras materias más útiles o de mayor eficacia para la vida [...]. Solo en la escuela universitaria puede existir el ambiente propicio para el estudio de lenguas muertas, que siendo de selección, no necesitan a toda la masa escolar, que a su vez, las resiste con tenaz empeño".

11 De acuerdo con el nuevo programa, la enseñanza de la gramática debía articularse con la composición, a partir de la cual se enseñaría durante el primer año "Analogía y Sintaxis hasta proposiciones y, durante el segundo año Sintaxis desde proposiciones, con exclusión del análisis lógico y ortología con exclusión de etimología” (González 1905: 19710).

12 El programa de Castellano para la reforma de 1903 es encargado a José Alfredo Ferreira (1863-1938). Con una extensa carrera en la docencia y en el Consejo Nacional de Educación, Ferreira era defensor del positivismo y el normalismo que, por esos años se imponía en la educación primaria (cfr. Dussel 1997). En consonancia con su voluntad didáctica renovadora, Ferreira organiza los contenidos del nuevo programa en tres secciones (A, B y C) para cada año. Para la sección A incluye la composición oral y escrita que, en principio, debe versar sobre los datos observados por el alumno y luego sobre los contenidos del programa. La sección B permanece inalterable durante los tres años y abarca ejercicios de lectura de obras nacionales y extranjeras. La sección C es propiamente gramatical (Ferreira 1903). Para un análisis más detallado de la cuestión véase Lidgett 2015.

13 De esta forma, según Di Tullio, "en ningún momento se pretendía 'enseñar la lengua', es decir, los aspectos regulares, puesto que se entendía que ya eran conocidos por el niño al ingresar a la escuela” (2002: 286); en cambio, en esta "cultura del idioma" estaban integrados los factores pertinentes para "un desempeño lingüístico aceptable en la vida social, como factores sociolingüísticos, sobre los que se asentaban los criterios que delimitaban las formas correctas de las incorrectas, factores estilísticos - registros, estilos y formatos discursivos-y factores pragmáticos, como la cortesía” (2002: 287).

14 La comisión de los Diez fue una comisión de especialistas encargada de revisar el estado de la segunda enseñanza en los Estados Unidos. En 1904, el Consejo Nacional de Educación encargó la publicación en la Argentina del Informe elabora por esta comisión (véase Comité de los Diez 1904).

15 La etimología como contenido obligatorio para Castellano aparece por primera vez en los programas de Castellano que elabora Baldmar Dobranich (1853-1912) en 1892, siguiendo el plan delineado por Carballido en 1891. Dobranich es autor de la Gramática histórica de la lengua castellana (1893 [31900]), cuya primera edición se publica como tercera parte de la Gramática castellana (1893) de Dobranich y Monner Sans. Los contenidos plasmados en esa tercera parte servirán de base para la sección de "Lingüística y etimología" presente en los programas de Castellano y en los textos oficiales desde 1892 hasta que la reforma de 1905 los suprime (cfr. Delgado 1947 y Lidgett 2012).

16 La comisión designada por el ministro Juan Garro estaba conformada por René Bastianini, Luis M. Díaz, Rómulo Martini, Luis Ricardo, Ricardo Monner Sans, Carlos H. Pizzurno, Eleuterio Tiscornia, Tomás Cullen, Adolfo de Cousandier, Manuel Derqui y Juan A. González Calderón. 